\title{
Study on the Atomization and Dust-Reduction Performance of a New Type of External Pneumatic Vortex Fog Curtain Dust Removal Device in Fully Mechanized Excavation Face
}

\author{
Deji Jing $\mathbb{D}^{1,2}$ Rina An, ${ }^{1,2}$ Jingxu Chen, ${ }^{1,2,3}$ Shaocheng Ge, ${ }^{1,2,4}$ and Liying Sun ${ }^{1,2,4}$ \\ ${ }^{1}$ Institute of Safely Science and Technology, Liaoning Technical University, Fuxin, Liaoning 123000, China \\ ${ }^{2}$ Key Laboratory of Mine Thermodynamic Disaster and Control of Ministry of Education, Fuxin 123000, China \\ ${ }^{3}$ Institute of Mining and Coal, Inner Mongolia University of Science and Technology, Baotou 014010, China \\ ${ }^{4}$ College of Safety and Emergency Management Engineering, Taiyuan University of Technical, Taiyuan 03000, China
}

Correspondence should be addressed to Deji Jing; jingdeji@lntu.edu.cn

Received 7 April 2020; Revised 20 June 2020; Accepted 25 June 2020; Published 26 July 2020

Academic Editor: Michael Aizenshtein

Copyright ( $\odot 2020$ Deji Jing et al. This is an open access article distributed under the Creative Commons Attribution License, which permits unrestricted use, distribution, and reproduction in any medium, provided the original work is properly cited.

\begin{abstract}
To solve the problem of dust pollution in the heading face, a new type of external pneumatic vortex fog curtain dust removal device suitable for a fully mechanized excavation face is designed in this paper. Firstly, dust migration laws at different times are simulated and analyzed by COMSOL software, and the functional relationship of dust concentration distribution above $50 \mathrm{mg} / \mathrm{m}^{3}$ at different heights and different wind speed is derived. Aiming at the dust migration laws of the heading face, a new dust removal device was proposed, and the atomization performance of the new type of external pneumatic vortex fog curtain dust removal device under different jet wind speed, different atomization pressure, and different nozzle working angle is explored through atomization performance experiment. It is found that when jet wind speed is $30 \mathrm{~m} / \mathrm{s}$, atomization pressure is $4 \mathrm{MPa}$, and nozzle working angle is $75^{\circ}$, the atomization performance of the new type of external pneumatic vortex fog curtain dust removal device is the best. Through the simulation of COMSOL software, the influence of air volume on the new type of external pneumatic vortex fog curtain dust removal device is analyzed. It is found that the new type of external pneumatic vortex fog curtain dust removal device is relatively stable when the air volume at the pressure outlet is less than $400 \mathrm{~m}^{3} / \mathrm{min}$. The dust-reduction efficiency of the new type of external pneumatic vortex fog curtain dust removal device was investigated through the dust-reduction experiment, and it is found that the new type of external pneumatic vortex fog curtain dust removal device had better dust removal performance under the condition that the ventilation conditions did not interfere with the integrity of the vortex fog curtain.
\end{abstract}

\section{Introduction}

As a country rich in coal, poor in oil, and low in gas, China's total coal energy use accounts for more than $65 \%$ of China's total energy consumption, and the energy use strategy based on coal resources will not change in the short term [1-3]. Most of the mining of coal resources is based on underground mining, and a large amount of dust will be generated during coal mining. Among them, dust pollution is serious during the process of coal breaking, coal discharging, and frame shifting $[4,5]$. The dust generated by the rotary coal breaking process of the cutting head or coal shearer occupies more than $80 \%$ of the total working dust, and the generated dust will spread to the entire tunneling face with the wind flow field, resulting in tunneling The concentration of dust in the work area far exceeds the national standard, so the problem of dust pollution control in underground mines has become a key problem and a difficult problem for domestic and foreign experts to pay attention to [6-8].

The fine dust and silicon dioxide generated during the tunneling process can easily penetrate the lungs of the human body through the respiratory system, causing lung cell damage and fibrotic damage to varying degrees [9]. Workers who have long worked underground in coal mines face a serious threat of lung disease, especially pneumoconiosis [10], and the treatment of pneumoconiosis requires 
high medical costs. According to the 2018 occupational disease report issued by the Ministry of Health of the People's Republic of China, about 23,000 coal workers are suffering from pneumoconiosis in China and $90 \%$ of whom are miners working in the excavation or mining face. Therefore, it is of great practical significance to reveal the laws of flour dust movement in tunneling work and to study related control measures. Yang et al. [11] used the gasparticle flow theory to analyze the dust distribution in the fully mechanized excavation face and simulated and analyzed the three-dimensional dust turbulent flow law in the fully mechanized excavation face by solving the simultaneous differential equations with the finite volume method. Wang et al. $[12,13]$ used Fluent software to simulate and analyze the ventilation system on the fully mechanized working face of the coal mine. They simulated and analyzed the impact of the rotary transverse disturbance of the digging head on the airflow field and the dust distribution. It finds that increasing the air curtain can significantly reduce the dust pollution. Cheng et al. $[14,15]$ proposed dust control technology based on a new type of air curtain generator. The ventilation airflow field and dust migration of a new type of air curtain generator in a fully mechanized working face was simulated by using the $k-\varepsilon$ two-equation turbulence model, Hertz-Mindlin model, and so on. The influence of dust diffusion and pollution behavior is achieved by changing different radial-axial forced pressure airflow rate ratios. Ge et al. [16-19] who from Liaoning Technology University adopted different spraying methods according to the characteristics of different digging working faces, and through a series of studies, such as optimizing atomization parameters of multiphase flow simulation technology, formed a system that the mechanism of jet atomization as theoretical foundation, dust-fog field simulation as technical core, and dust-reduction parameter optimization as development motive force.

According to the dust movement rule of the tunneling work and the research on dust pollution control by scholars at home and abroad, this paper combines the method of air curtain dust control and atomization dust removal and uses pneumatic vortex fog curtain to control the flour dust. At present, comprehensive dust control system of pneumatic vortex fog curtain and underground dust control work is mostly based on human subjective experience, lack of corresponding equipment control system, and lack of complete theoretical analysis. Considering the technical characteristics and atomization method of air curtain, a new type of external pneumatic vortex fog curtain dust removal device installed on a roadheader is studied in this paper, which makes the combination of droplets and dust more closely and effectively prevent the diffusion of dust. The dust movement law is deduced through numerical simulation analysis, which provides a theoretical basis for designing a new type of external pneumatic vortex fog curtain dust removal device. In order to accurately analyze the designed dust removal device, the atomization and dust removal performance under different conditions were controlled. The experimental results show that the device has good dedusting effect.

\section{Numerical Simulation and Analysis of Dust Escape Law of Fully Mechanized Excavation Face}

\subsection{Mathematical Model}

2.1.1. Continuous Phase Equation. Continuous equation:

$$
\frac{\partial \rho}{\partial t}+\nabla \cdot(\rho V)=0
$$

where $\rho$ is the density, $\mathrm{g} / \mathrm{cm}^{3}$; $t$ is the time, $s$; and $V$ is the velocity vector.

Momentum equation:

$$
\begin{aligned}
& \frac{\partial\left(\rho V_{x}\right)}{\partial t}+\nabla\left[\rho V_{y} V\right]=\nabla \cdot\left(\mu \operatorname{grad} V_{x}\right)-\frac{\partial \rho}{\partial x}+S_{x}, \\
& \frac{\partial\left(\rho V_{y}\right)}{\partial t}+\nabla\left(\rho V_{y} V\right)=\nabla \cdot\left(\mu \operatorname{grad} V_{y}\right)-\frac{\partial \rho}{\partial y}+S_{y}, \\
& \frac{\partial\left(\rho V_{z}\right)}{\partial t}+\nabla\left(\rho V_{z} V\right)=\nabla \cdot\left(\mu \operatorname{grad} V_{z}\right)-\frac{\partial \rho}{\partial z}+S_{z},
\end{aligned}
$$

where $V_{x}, V_{y}$, and $V_{z}$ are the velocity components on the $x$, $y$, and $z$ axes, $\mathrm{m} / \mathrm{s} ; \mu$ is hydrodynamic viscosity, Pa.s; and $S_{x}$, $S_{y}$, and $S_{z}$ are the source terms on the $x, y$, and $z$ axes, respectively.

\subsubsection{Discrete Phase Equation.}

$$
\begin{aligned}
\frac{\mathrm{d} u_{\mathrm{pl}}}{\mathrm{d} t} & =F_{d}\left(u_{g}-u_{\mathrm{pl}}\right)+\frac{g\left(\rho_{\mathrm{pl}}-\rho_{g}\right)}{\rho_{\mathrm{pl}}}+F, \\
F_{d} & =\frac{18 \mu}{\rho_{\mathrm{pl}} d_{\mathrm{pl}}^{2}} \cdot \frac{C_{d} \mathrm{Re}}{24},
\end{aligned}
$$

where $\rho_{\mathrm{g}}$ is the gas density, $\mathrm{g} / \mathrm{cm}^{3} ; \rho_{\mathrm{pl}}$ is the liquid density, $\mathrm{g} / \mathrm{cm}^{3} ; u_{g}$ is the gas velocity, $\mathrm{m} / \mathrm{s} ; u_{\mathrm{pl}}$ is the liquid velocity, $\mathrm{m} /$ $s ; F_{d}$ is the unit drag force of the droplet, $\mathrm{N} ; d_{\mathrm{pl}}$ is the liquid drop diameter, $m$; Re is the Reynolds number; $C_{d}$ is the drag coefficient; $g$ is the acceleration of gravity, $\mathrm{m} / \mathrm{s}^{2}$; and $F$ is the other force, $\mathrm{N}$.

2.1.3. Crushing Model of Droplet Particles in Turbulent Flow. Most of the rupture models of droplets in the turbulent flow field are based on the improved Kolmogorov and Hinze models. The calculation formula of the obtained critical Weber number is

$$
W e_{l}=\frac{\rho_{g} u^{2} d_{l \max }}{\sigma}
$$

where $u$ is the air turbulence pulsation velocity on the surface of the droplet particles, $u^{2}=2\left(E d_{l \max }\right)^{2 / 3}$, $d_{l \max }=C\left(\sigma / \rho_{g}\right)^{3 / 5} E^{-2 / 5}$, and $C$ is 0.725 .

2.1.4. Atomization and Crushing Model. Kelvin-Helmholtz (K-H) model is used for the numerical simulation of the secondary breaking atomization of the nozzle. The $\mathrm{K}-\mathrm{H}$ 
model assumes that the jet diameter at the nozzle outlet, the incompressible high-pressure liquid is injected into the gas flow field through a small round hole, and the maximum frequency $\left(\Omega_{\mathrm{KH}}\right)$ and the growth wavelength $\left(\Lambda_{\mathrm{KH}}\right)$ are obtained under the corresponding conditions, and the calculation formula is as follows:

$$
\begin{aligned}
\Lambda_{\mathrm{KH}} & =\frac{9.02 r_{0}(1+0.45 \sqrt{Z})\left(1+0.4(T)^{0.7}\right)}{\left(1+0.865 W e_{l}^{1.67}\right)^{0.6}}, \\
\Omega_{\mathrm{KH}} & =\frac{0.34+0.385 W e_{l}^{1.5}}{(1+Z)\left(1+1.4 T^{0.6}\right)} \sqrt{\frac{\sigma}{\rho_{l} r_{0}^{2}}},
\end{aligned}
$$

where $W e_{l}$ is the Weber number of the liquid, $W e_{l}=\rho_{l} U_{r}^{2} d_{l} / \sigma$, where $U r$ is the relative velocity between the liquid phase and the gas phase, $d_{l}$ is the characteristic length, $\sigma$ is the surface tension coefficient, and $\rho_{l}$ is the density of the liquid phase; $Z$ is the onset number, $Z=\sqrt{W e_{l}} / \operatorname{Re}_{l}$, $\operatorname{Re}_{l}=\rho_{l} U_{r}^{2} r / \mu_{l}$, and $\mu_{1}$ is the viscosity of the liquid; $T$ is the Taylor number, $T=Z \sqrt{W e_{l}}$, and $r_{0}$ is the droplet breaking radius.

During the crushing process, the time change rate and scale change of the main droplets are calculated as follows:

$$
\frac{\mathrm{d} r}{\mathrm{~d} t}=-\frac{r_{0}-r_{\mathrm{KH}}}{\tau_{\mathrm{KH}}}
$$

where $\tau_{\mathrm{KH}}$ is the time scale of $\mathrm{K}-\mathrm{H}$ crushing, $\tau_{\mathrm{KH}}=3.788 B_{1} r_{0} / \Lambda_{\mathrm{KH}} \Omega_{\mathrm{KH}} ; B_{1}$ is the empirical constant, generally $1.73-40$, which is 4.04 .

Based on the theory of liquid jet stability, small subdroplets are peeled off from the surface of the main droplet. The size of the newly generated small droplets is proportional to the fastest growing wavelength of the surface wave. Then, the radius of droplet breakup is

$$
r=\left\{\begin{array}{c}
B_{0} \Lambda_{\mathrm{KH}},\left(B_{0} \Lambda_{\mathrm{KH}} \leq a\right), \\
\min \left\{\left(\frac{3 \pi a^{2} U_{r}}{2 \Omega_{\mathrm{KH}}}\right)^{0.33},\left(\frac{3 a^{2} \Lambda_{\mathrm{KH}}}{4}\right)\right\},\left(B_{0} \Lambda_{\mathrm{KH}}>a\right),
\end{array}\right.
$$

where $B_{0}$ is the model constant and takes 0.61 .

2.1.5. Collision Model. Considering that the main collision and aggregation between fog droplets, the critical value obtained by Rourke is used to describe the collision model:

$$
\begin{aligned}
S_{t k} & =\frac{\rho_{\mathrm{pl}} d_{\mathrm{pl}}^{2}}{18 \rho_{g} \mu(\nu / \varepsilon)^{1 / 2}}=\frac{\rho_{\mathrm{pl}}}{18 \rho_{g}}\left[\frac{d_{\mathrm{pl}}}{\left(\nu^{3} / \varepsilon\right)^{1 / 4}}\right], \\
\eta & =\left(\frac{S_{t k}}{S_{t k}+a}\right)^{b},
\end{aligned}
$$

where $S_{t k}$ is the Stokes number, dimensionless; $v$ is the air kinematic viscosity, $\mathrm{m}^{-2} \mathrm{~s}^{-1} ; \varepsilon$ is the turbulent dissipation rate, dimensionless; $\eta$ is the collision efficiency; $a$ and $b$ are the parameters related to the Reynolds number, $a$ takes 0.65 and $b$ takes 3.7.
2.1.6. $k$ - $\varepsilon$ Turbulence Model. Based on the theory of gas-solid two-phase flow, the dust particle phase uses a linear twoequation $\mathrm{k}-\varepsilon$ turbulence model to describe the movement of air, analyze the force of the dust particles in the gas-phase wind velocity flow field, and establish the dynamic model and motion equation of dust particles in confined space. The force acting on the particles can be expressed by the classic Newton's second law equation as follows $[20,21]$ :

$$
m_{p}=\frac{\mathrm{d} u_{p}}{\mathrm{~d} t}=F_{g}+F_{f}+F_{d}+F_{x} .
$$

The continuous equation, momentum equation, and $\mathrm{k}-\varepsilon$ turbulence model equation of dust particle phase are as follows [22-24]:

Turbulent kinetic energy equation:

$$
\frac{\partial(\rho k)}{\partial t}+\frac{\partial\left(\rho k u_{i}\right)}{\partial x_{i}}=\frac{\partial}{\partial x_{i}}\left[\left(\mu+\frac{\mu_{i}}{\sigma_{k}}\right) \frac{\partial(k)}{\partial x_{j}}\right]+G_{k}-\rho \varepsilon .
$$

Turbulent energy dissipation rate equation:

$$
\frac{\partial(\rho \varepsilon)}{\partial t}+\frac{\partial\left(\rho \varepsilon u_{i}\right)}{\partial x_{i}}=\frac{\partial}{\partial x_{i}}\left[\left(\mu+\frac{\mu_{i}}{\sigma_{\varepsilon}}\right) \frac{\partial(\varepsilon)}{\partial x_{j}}\right]+\rho C_{1} E \varepsilon-\rho C_{2} \frac{\varepsilon^{2}}{k+\sqrt{v \varepsilon}} .
$$

Turbulent viscosity $\mu_{t}$ can be expressed as

$$
\mu_{t}=\rho C_{\mu} \frac{k^{2}}{\varepsilon}
$$

where $m_{p}$ is mass of solid particles, $m_{g} ; u_{p}$ is the velocity of the solid particles, $\mathrm{m} / \mathrm{s} ; F_{d}$ is the resistance of particles, $\mathrm{N} ; F_{g}$ is the particle's own gravity, $\mathrm{N} ; F_{f}$ is the air buoyancy of the particles, $\mathrm{N}$; and $F_{x}$ is other force acting on the particles, $\mathrm{N}$, where $G_{k}=\mu_{g} E^{2}$ and $\mu_{g}$ is the viscosity coefficient; $C_{1}=\max$ $[0.43, \eta /(\eta+5)]$ and $\eta=E k / \varepsilon ; C_{2}$ is constant and takes 1.9; $E=\sqrt{2 E_{i j} E_{i j}} ; \sigma_{k}$ and $\sigma_{\varepsilon}$ are turbulent Prandtl coefficients of turbulent energy equation and turbulent energy dissipation rate equation, which are 1.0 and 1.2 , respectively, where

$$
\begin{aligned}
C_{\mu} & =\frac{1}{\left(A_{0}+A_{s} U^{*} k / \varepsilon\right)}, \quad A_{0}=4.0, A_{s}=\sqrt{6 \cos \phi}, \\
\phi & =\frac{1}{3} \arccos (\sqrt{6 W}), \\
W & =\frac{E_{i j} E_{j k} E_{k j}}{\left(E_{i j} E_{i j}\right)^{0.5}}
\end{aligned}
$$

$W$ is power, $W$,

$$
\begin{aligned}
E_{i j} & =0.5\left(\frac{\partial u_{i}}{\partial x_{i}}+\frac{\partial u_{j}}{\partial x_{j}}\right), \\
U^{*} & =\sqrt{E_{i j} E_{i j}+\widetilde{\Omega}_{i j} \widetilde{\Omega_{i j}}},
\end{aligned}
$$

$U^{*} \quad$ is internal energy, $J ; \quad \Omega_{i j}=\widetilde{\Omega}_{i j}-\varepsilon_{i j k} \omega_{k}$; $\widetilde{\Omega}_{i j}=\Omega_{i j}-2 \varepsilon_{i j k} \omega_{k}, \widetilde{\Omega}_{i j}$ is the time-averaged rotation rate tensor with angular velocity $\omega_{k}$ as a reference system, and it includes the influence of rotational flow; $\widetilde{\Omega}_{i j}$ is the similar value of $\Omega_{i j}$. 
2.1.7. Gas-Solid Drag Model. The Schiller-Naumann model, a common drag model, is selected for calculation, and the drag force of dust particles is as follows $[25,26]$ :

$$
F_{D}=\frac{1}{\tau_{p}} m_{p}\left(v_{g}-v_{p}\right) \text {, }
$$

where

$$
\begin{aligned}
\tau_{p} & =\frac{4 \rho_{p} d_{p}^{2}}{3 \mu C_{d} \operatorname{Re}_{r}}, \\
C_{d} & =\frac{24}{\operatorname{Re}_{r}}\left(1+0.15 \operatorname{Re}_{r}^{0.687}\right), \\
\operatorname{Re}_{p} & =\frac{\rho\left|U_{g}-U_{p}\right| d_{p}}{\mu},
\end{aligned}
$$

$\operatorname{Re}_{p}$ is the particle Reynolds function.

2.1.8. Near-Wall Treatment. When the particles collide with the wall, the damping force and the elastic force are applied to the normal direction of the particle motion, which is the second and the first terms on the right side of the equation, respectively. The calculation formula of the upward normal force is as follows [27]:

$$
F_{n w, i j}=-\left(k_{n w, i} \delta_{n, i j}\right) n_{i}-\eta_{n w, i}\left(v_{i j} \cdot n_{i}\right) n_{i},
$$

where $k_{n w, i}$ is the particle-wall normal elastic coefficient; $\delta_{n . i j}$ is the relative normal displacement, $m ; \eta_{n w, i}$ is the damping coefficient; $n_{i}$ is the unit vector of particle $i$ normal; and $v_{i j}$ is the relative velocity vector of particles $j$ and $i$.

In the process of dust particles colliding with the wall surface, assuming the wall surface is stationary, then $v_{i j}=v_{i}$,

$$
\begin{aligned}
k_{n w} & =k_{n}=\frac{4 \sqrt{2 R_{i}}}{\sqrt{\left(1-\sigma_{s}^{2} / E_{S}\right)+\left(1-\sigma_{w}^{2} / E_{W}\right)}}, \\
\delta_{n, i j} & =\delta_{n}=R_{i}-\left|\left(x y z_{i}-x y z_{w}\right) \cdot n\right|, \\
\eta & =a_{n}\left(m k_{n}\right)^{1 / 2} \delta_{n}^{1 / 4} .
\end{aligned}
$$

Similar to the normal force calculation process, the calculation formula of the tangential force $F_{t w, i j}$ for particlewall collision is as follows:

$$
F_{t w, i j}=-k_{t w, i} \delta_{t, i j}-\eta_{t, i} v_{t w, i j}
$$

where

$$
\begin{aligned}
& v_{t w, i j}=v_{i j}-\left(v_{i j} \cdot n\right) n+L_{i} \omega_{i} n, \\
& k_{t w, i}=k_{t}=\frac{8 \sqrt{R_{i}} E_{S}}{2\left(2-\sigma_{s}\right)\left(1+\sigma_{s}\right)} \delta_{n}^{1 / 2} .
\end{aligned}
$$

2.2. Physical Models. To accurately simulate the distribution of dust movement in the heading face, this paper sets up a physical model according to the measurement results of the actual size of the heading face in the underground coal mine of Mugua coal mine in Huozhou, Shanxi Province. The physical model is composed of three parts: roadheader model, pneumatic vortex fog curtain model, and roadheader model. The roadheader model is a rectangle with a length of $20 \mathrm{~m}$, a width of $4.5 \mathrm{~m}$, and a height of $3.5 \mathrm{~m}$. The roadheader model with a length of $9.3 \mathrm{~m}$ is placed in the roadheader model.

For the convenience of calculation, the cylinder center point of the cutting section of the roadheader model is used as the origin, and the positive $z$-axis direction is perpendicular to the top of the roadway from the origin, the positive $y$-axis direction is perpendicular to the right side wall of the roadway from the origin, and the positive $x$-axis direction is perpendicular to the outlet of the roadway from the origin. Point vertically to the air outlet of the tunnel. The aerodynamic vortex fog curtain generator model has an outer diameter of $1.1 \mathrm{~m}$, an inner diameter of $0.9 \mathrm{~m}$, a central axis height of $1.75 \mathrm{~m}$, and a horizontal position of $y=0$; the highpressure air current ejector is evenly arranged on the inclination wall surface of the ring-mounted air duct. On the outside, four nozzles with a diameter of $0.02 \mathrm{~m}$ are arranged on the periphery of the ring-mounted air duct. The physical model of the fully mechanized excavation face is shown in Figure 1. In this paper, COMSOL software is used to mesh the established three-dimensional physical model. There are three grid cell sizes, which are conventional, coarser, and extremely coarse. The total number of grids is 255023, 740135 , and 2450349. The minimum unit mass is 0.07468 , 0.1305 , and 0.09265 . The proportions of the mesh quality exceeding 0.4 under the three divisions are $0.981,0.988$, and 0.991, respectively, indicating that the three mesh divisions are reasonable and the calculation is accurate. Considering the calculator's ability to process data, this article chooses a coarser grid division, the total number of grid divisions is 740135 , and the simulation calculation time is 72 hours. The meshing diagram is shown in Figure 2.

In the COMSOL simulation, the interior space of the roadway model is defined as the calculation domain, the outlet of the high-pressure airflow ejector of the annular air duct is regarded as the gas-phase wind speed inlet, and the exit end of the roadheader is regarded as the "outlet" boundary. The droplet particles are affected by drag force and gravity in the fluid flow, and then dynamic events such as collision, aggregation, and secondary crushing occur. The gas-phase material is air, and the liquid phase material is water. The materials used are provided by the COMSOL's database. The gas phase is regarded as a continuous phase, the droplet particles are regarded as a discrete phase, the wall conditions are set to freeze, the $\mathrm{k}-\varepsilon$ turbulence model is used, the droplet second crushing adopts the K-H crushing model, and there is no energy exchange between the gas and liquid phases, and the coupling between the calculation of the phase until iterative convergence. The initial ambient temperature is $293 \mathrm{~K}$, and the pressure is standard atmospheric pressure.

2.3. Dust Concentration Diffusion Simulation. The basic boundary conditions of the flow field movement law of the physical model of the fully mechanized excavation face are 


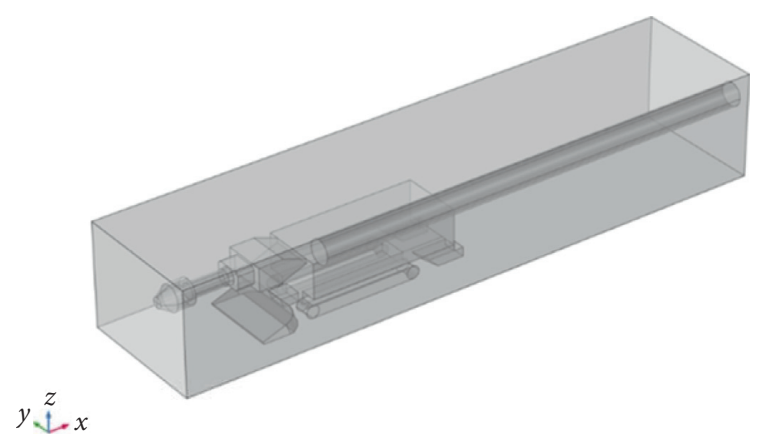

Figure 1: Physical model of the fully mechanized excavation face.
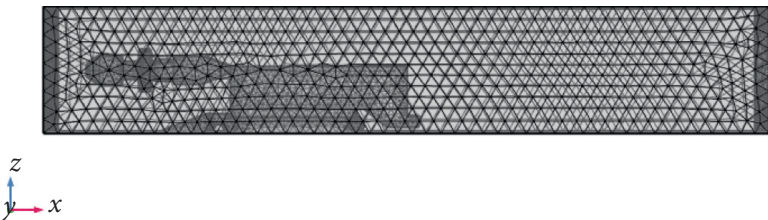

FIgURe 2: Meshing of the physical model of fully mechanized excavation face.

set as follows: the entrance boundary is the velocity field entrance; the exit is the fully developed heading lane airflow exit. Roadway sectional area is $15.75 \mathrm{~m}^{2}$, air compressor duct diameter is $0.8 \mathrm{~m}$, the outlet from the excavation surface is $5 \mathrm{~m}$, and the amount of pressure outlet cross-sectional area of common setting air volume is $300 \mathrm{~m}^{3} / \mathrm{min}$ for this heading roadway. Based on this, COMSOL numerical simulation software was used to simulate the movement of the wind field in confined space.

2.3.1. The Movement Law of Dust at Different Times. The simulation results are shown in Figure 3. The particle trajectory in the figure intuitively shows the diffusion of dust particles in the working space of the excavation face at the five moments of $t=2 \mathrm{~s}, t=4 \mathrm{~s}, t=6 \mathrm{~s}, t=8 \mathrm{~s}$, and $t=10 \mathrm{~s}$. As can be seen from Figure 3,

(1) Dust particles generated by cutting coal by the roadheader are mainly concentrated near the roadheader, and dust particles settle in large quantities near the lower part of the roadheader.

(2) During the whole falling process, dust particles are impacted and entrapped by wind currents and migrate to the exit by spiraling.

(3) The diffusibility of the dust particles under the action of the airflow of the pressure outlet is good, and the diffusion speed on the cutting head to the working space is very fast. Meanwhile, dust particles are influenced by gravity, resulting in relatively more dust particles in the heading area.

2.3.2. Dust Concentration Field in Different Sections in $X$ Axis Direction. To visually display the distribution of dust concentration in the working space of fully mechanized excavation face, the cross sections of the numerical simulation results of dust concentration at $X=0 \mathrm{~m}, X=2.5 \mathrm{~m}$, $X=7.5 \mathrm{~m}, X=10 \mathrm{~m}, X=12.5 \mathrm{~m}, X=15 \mathrm{~m}$, and $X=17.5 \mathrm{~m}$ were selected along the $x$-axis of the calculation model. The overall change trend of dust concentration was shown in Figure 4 . It can be seen from Figure 4:

At $X=0-2.5 \mathrm{~m}$, dust particles fall from the heading-point in the restricted space and then get into the gas-phase flow field area of the heading face. The simulation results demonstrate that the highest dust concentration can reach $1,188.9 \mathrm{mg} / \mathrm{m}^{3}$.

In the section of $X=5-10 \mathrm{~m}$, due to the wind-wrapping effect of the pressure outlet, the dust particles diffuse along the roadway in the direction of transportation along the roadway. Due to the vortex at the tail of the roadheader, the machine dust accumulation occurs at the tail, and the dust concentration rises. At $X=10 \mathrm{~m}$, the dust concentration in the working space reaches $167 \mathrm{mg} / \mathrm{m}^{3}$. Under the action of aerodynamics, dust particles in the restricted space of the heading line move around randomly under the influence of airflow field. At the same time, dust particles with larger particle size slowly settle under the combined action of gravity and resistance, while dust particles with smaller particle size continue to spread forward and the dust concentration is still decrease.

2.4. Dust Concentration Analysis and Discussion. To analyze the influence of airflow on the air outlet on the dust pollution of dust particles, the influence of three different heights $\mathrm{H}$ on the dust concentration in the working space was selected, and the $X Y$ scattered point data are derived and plotted, respectively. Set the air volume of the pressure outlet to $150 \mathrm{~m}^{3} / \mathrm{min}, 400 \mathrm{~m}^{3} /$ min, and $500 \mathrm{~m}^{3} / \mathrm{min}$. Select three different heights $Z$, which are $1 \mathrm{~m}, 1.5 \mathrm{~m}$, and $2 \mathrm{~m}$. Select the dust concentration data at $Y=1.2 \mathrm{~m}$ and $X=0-20 \mathrm{~m}$. The dust concentration distribution is shown in Figure 5, using software Origin9.0 to draw the relationship between the air volume and the diffusion distance $L(\mathrm{~m})$ of high-concentration dust above $50 \mathrm{mg} / \mathrm{m}^{3}$ and using MATLAB software to fit. The diffusion concentrations of dust at different heights are as follows:

$$
\left\{\begin{array}{l}
y=-1.5 \times 10^{-7} x^{3}+0.0001 x^{2}-0.0268 x+5.2771, H=1 \mathrm{~m}, \\
y=-2.8 \times 10^{-7} x^{3}+0.0004 x^{2}-0.1021 x+13.546, H=1.5 \mathrm{~m}, \\
y=-1.8 \times 10^{-7} x^{3}+0.0002 x^{2}-0.05 x+10.677, H=2 \mathrm{~m},
\end{array}\right.
$$

where $x$ is the air volume of the pressure outlet and $y$ is the diffusion distance.

It can be seen from Figure 5 that as the air volume of the pressure outlet increases, the kinetic energy of dust increases, and the dust concentration increases with the increase of wind speed. Even if the air volume of the pressure outlet is increased from $150 \mathrm{~m}^{3} / \mathrm{min}$ to $500 \mathrm{~m}^{3} / \mathrm{min}$, the dust concentration at the height $\mathrm{H}$ is still the highest at $1.5 \mathrm{~m}$.

Figure 6 shows the distribution rule of diffusion distance $L$ of high-concentration dust under three different ventilation conditions. Dust diffusion distance $L$ changes with the change of ventilation conditions. When the measuring point is set at $H=1 \mathrm{~m}$, the dust diffusion distance $L$ increases first 


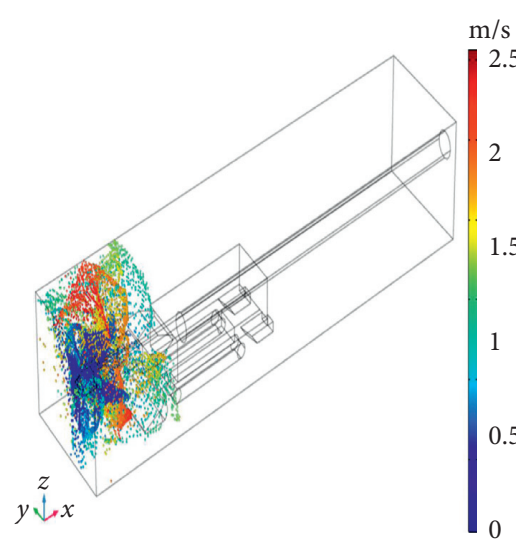

(a)

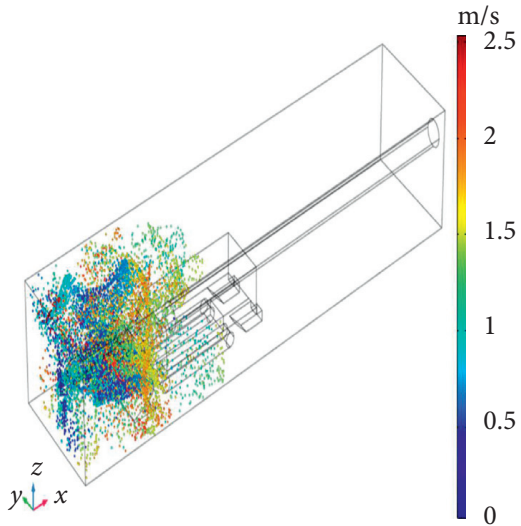

(b)

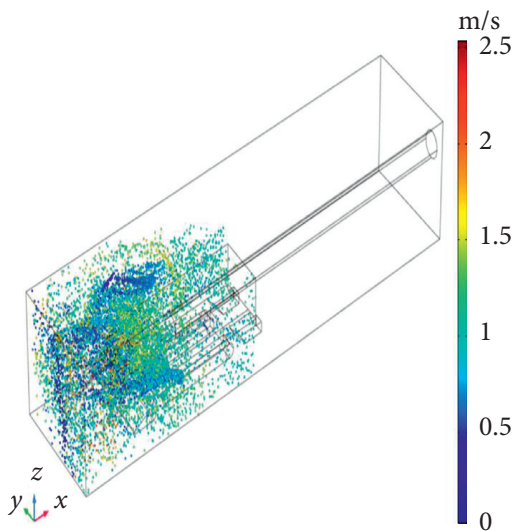

(c)

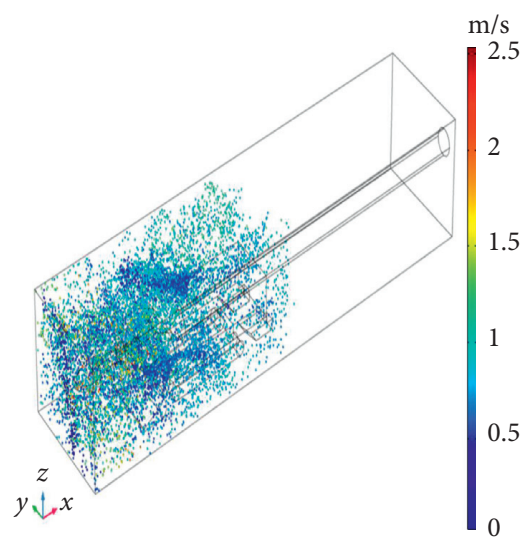

(d)

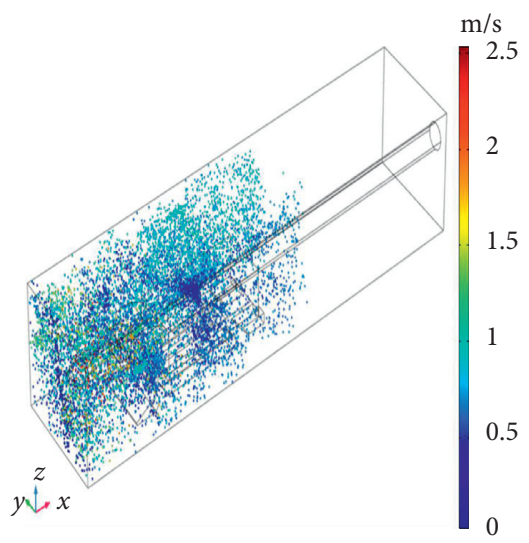

(e)

Figure 3: Trajectory of dust particles: (a) $t=2 \mathrm{~s}$, (b) $t=4 \mathrm{~s}$, (c) $t=6 \mathrm{~s}$, (d) $t=8 \mathrm{~s}$, and (e) $t=10 \mathrm{~s}$.

and then decreases with the increase of air volume at the pressure outlet, so the air volume rises from $3.5 \mathrm{~m}$ at $150 \mathrm{~m}^{3} /$ min to $6 \mathrm{~m}$ at $400 \mathrm{~m}^{3} / \mathrm{min}$, and then the dust diffusion distance $L$ decreases. This is explained by the fact that the dust particles are increased by the air impact of the pressure outlet, and the highconcentration dust continues to move upward, resulting in a decrease in the dust concentration at a height of $1 \mathrm{~m}$. When $H=1.5 \mathrm{~m}$ and $H=2 \mathrm{~m}$ are set at the measuring point, the diffusion distance $L$ of high-concentration dust will gradually expand with the increase of air volume. When the air volume at the pressure outlet is $500 \mathrm{~m}^{3} / \mathrm{min}$ and the measuring point is $H=2 \mathrm{~m}$, the diffusion distance of high-concentration dust is the farthest, which is $7.5 \mathrm{~m}$. This shows that the impact dust of the pressure air curtain formed by the pressure air duct diffuses to the whole roadway, resulting in the dust floating in all positions during the construction process. Therefore, it is urgent to choose a new dust control system that can achieve a better dust control effect to solve the dust pollution in the heading face.

\section{Structure and Experiment of a New Type of External Pneumatic Vortex Fog Curtain Dust Removal Device}

3.1. Device Structure. Compared with the traditional external annular atomizing dust suppression device, the new type of external pneumatic vortex fog curtain dust removal device combines the external annular atomize with the pneumatic air curtain. A new type of external pneumatic vortex fog curtain dust removal device is located at the front of the roadheader arm, and after the heading of the roadheader, it appears in a "ring" shape. The outer ring is high-pressure atomization, while the inner ring is pneumatic vortex air curtain. The fog curtain formed by the high-pressure nozzle is diffused outward by the vortex flow field formed from the pneumatic vortex air curtain. The new type of external pneumatic vortex fog curtain dust removal device is composed of six parts, including the air inlet duct, the water supply pipe, the ring-mounted air duct, the ringmounted water pipe, the high-pressure airflow ejector, and the nozzle, as shown in Figure 7. The air inlet duct is connected to a ring-mounted air duct, the ring-mounted air duct is inclined inward $15^{\circ}$, and 24 high-pressure airflow ejectors are arranged on the ring-mounted air duct at an equal interval. The water supply pipe is arranged along the air inlet duct, which is connected to the ring-mounted water pipe, and the ring-mounted water pipe is outside the ring-mounted air duct. The six nozzles are evenly arranged on the ring-mounted water pipe at $45^{\circ}$ intervals, all of which are facing the working direction of the cutting head. 


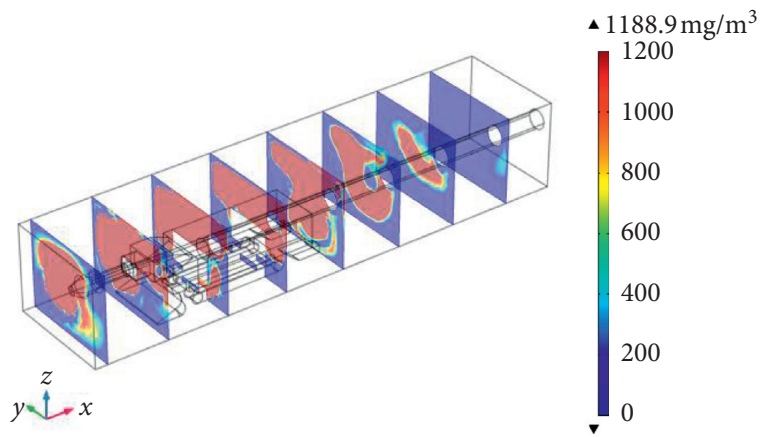

(a)

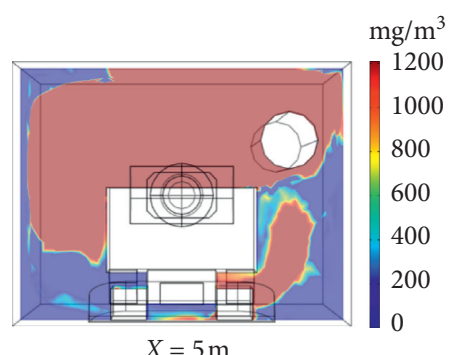

(d)

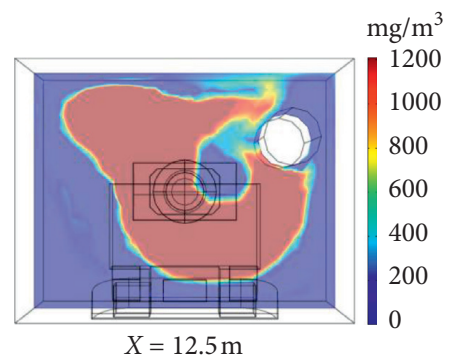

(g)

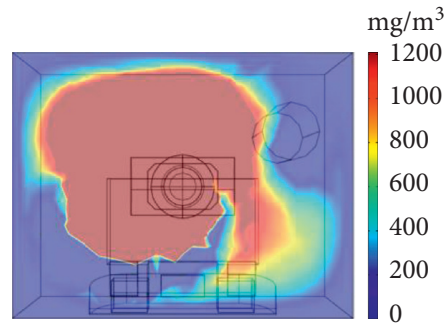

$X=0 \mathrm{~m}$

(b)

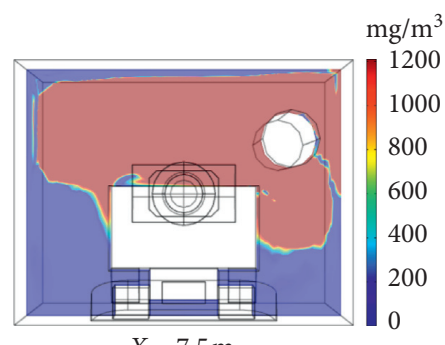

(e)

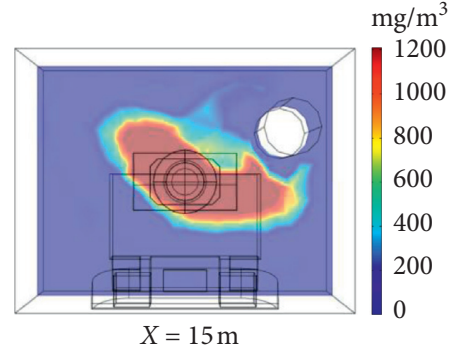

(h)

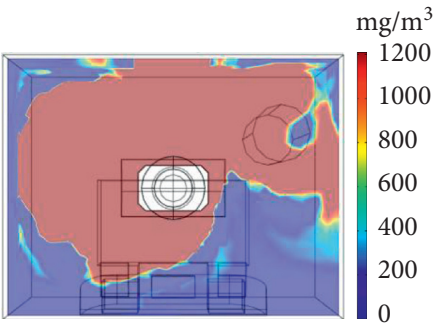

$X=2.5 \mathrm{~m}$

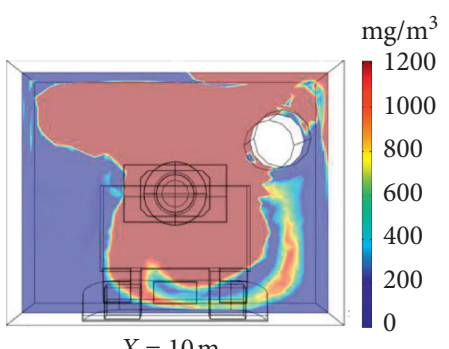

(f)

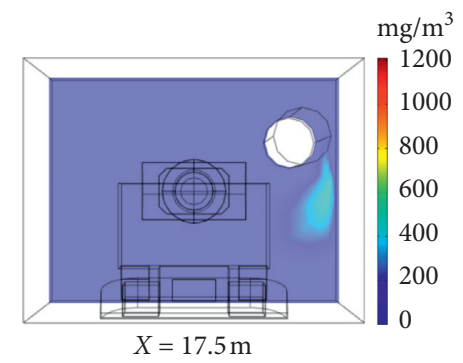

(i)

FIGURE 4: Simulation of dust concentration field in different cross sections in the $x$-axis direction.

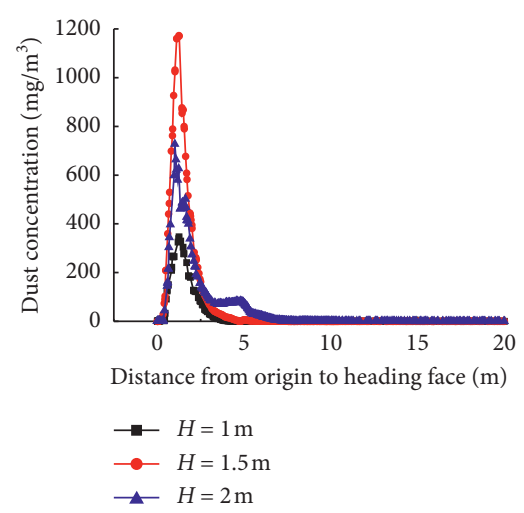

(a)

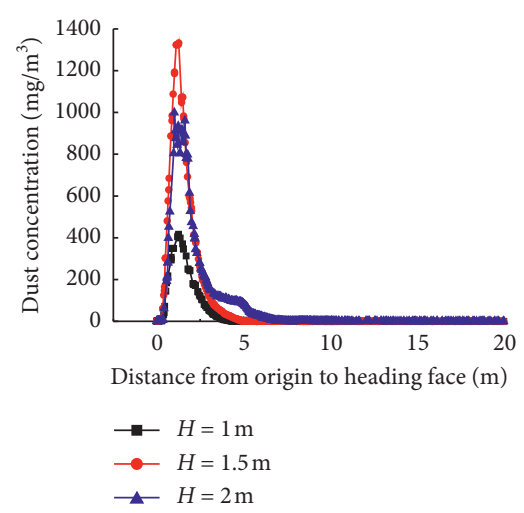

(b)

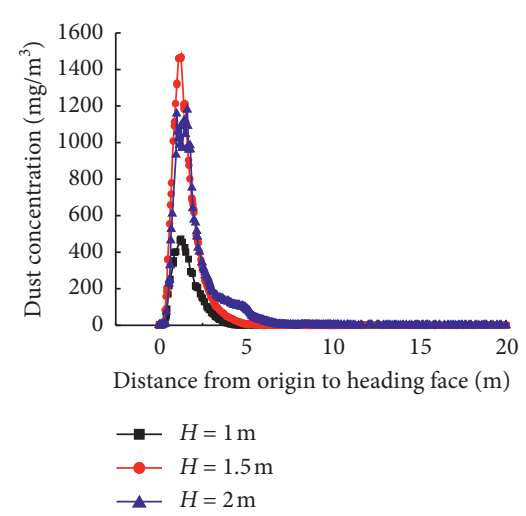

(c)

FIGURE 5: Effect of dust concentration in working space: (a) $v=150 \mathrm{~m}^{3} / \mathrm{min}$, (b) $v=400 \mathrm{~m}^{3} / \mathrm{min}$, and (c) $v=500 \mathrm{~m}^{3} / \mathrm{min}$.

3.2. Working Mechanism. In the process of atomization dust control by the pneumatic vortex fog curtain dust control system of the roadheader, the use of atomization alone for dust control often does not achieve effective dust control performance, which requires the pneumatic air curtain and atomization to be treated simultaneously. The working process of the new type of external pneumatic vortex fog curtain dust removal device consists of three steps. Firstly, 


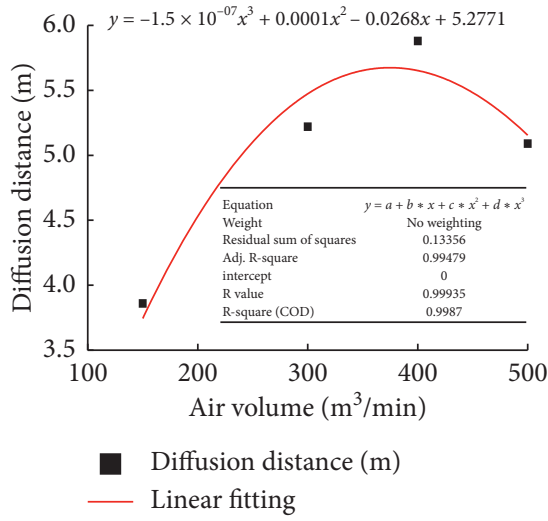

(a)

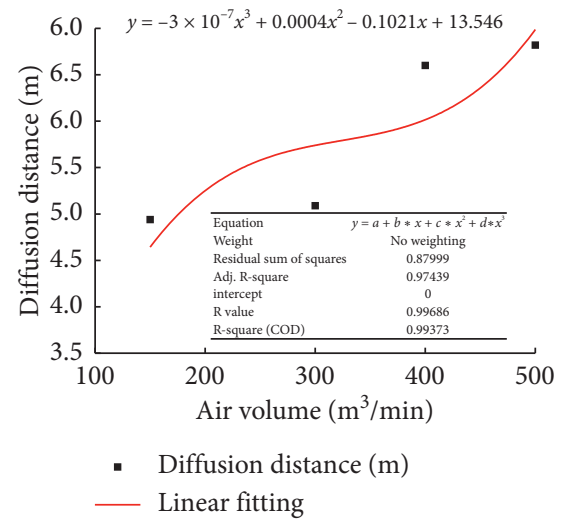

(b)

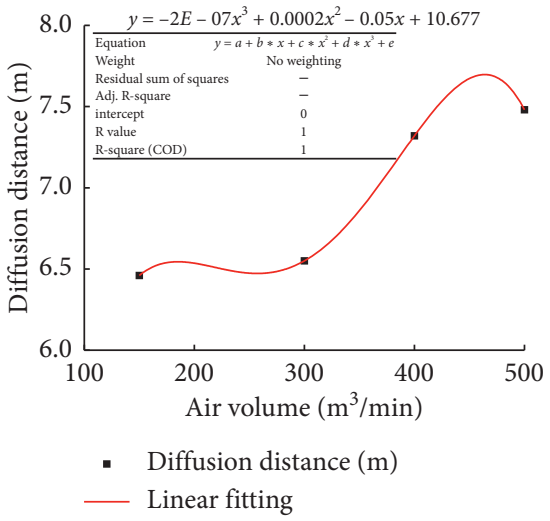

(c)

FIGURE 6: Influence of different heights on the diffusion distance of dust concentration in the working space: (a) $H=1 \mathrm{~m}$, (b) $H=1.5 \mathrm{~m}$, and (c) $H=2 \mathrm{~m}$.

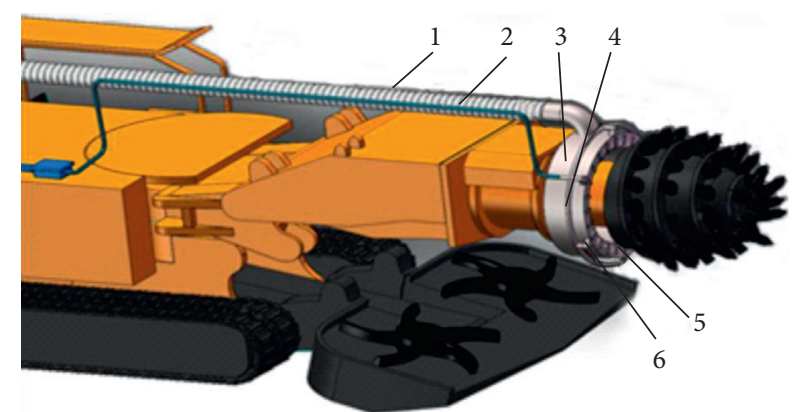

Figure 7: Schematic diagram of device structure ((1) air inlet duct, (2) water supply pipe, (3) ring-mounted air duct, (4) ring-mounted water pipe, (5) high-pressure airflow ejector, and (6) nozzle).

the airflow in the air inlet duct is directed to the highpressure airflow ejector through the ring-mounted air duct to form the multiple high-speed jet. The interaction between the jet boundary layer and the surrounding gas makes the spray center show a negative pressure gas field, which sucks the surrounding gas to form a pneumatic vortex air curtain.

Secondly, the water in the water supply pipe is led to the nozzle through the ring-mounted water pipe, and the water is broken and atomized into mist droplets through the nozzle, and the droplets diffuse to the surrounding of the roadheader at high speed. Due to the impact of the vortex jet gas, the mist droplets are broken up into smaller droplets. Finally, the droplet's movement direction changes due to the influence of the pneumatic vortex air curtain, and the droplet acquires tangential kinetic energy, and rotates and diffuses outward. Compared to the traditional spray dustreduction method, the droplet size of the new type of external pneumatic vortex fog curtain dust removal device is smaller and the atomization effect is better. It can better seal the cross section of the roadway, wrap the dust source, and effectively isolate the dust movement.

3.3. Research Parameters of Atomization Performance. To study the atomization performance of the new type of external pneumatic vortex fog curtain dust removal device, atomization range and atomization radius of the pneumatic vortex fog curtain are used to characterize the atomization performance of the device. The control variable method was utilized to investigate the atomization performance of the device from three aspects: jet wind speed, atomization pressure, and nozzle working angle.

However, since the dust removal device will be affected by the viscosity of the liquid and the airflow in the roadway in the actual application process, there will be a deviation between the atomization range and the atomization radius of the pneumatic vortex fog curtain. For the convenience of research, the distance from the nozzle to the front end of the pneumatic vortex fog curtain is taken as the atomization range and is represented by the letter $\mathrm{D}$; the radius of the theoretical spray range is taken as the atomization radius and is represented by the letter R, as shown in Figure 8.

3.4. Atomization Performance Experiment. The atomization performance experiment platform is composed of three parts: air curtain generator, atomization system, and experimental area. The air curtain generator includes vector frequency converter, centrifugal fan, air inlet duct, ringmounted air duct, high-pressure airflow ejector, and thermal anemometer. The atomization system includes a water tank, high-pressure atomizer, pressure regulating controller, pressure gauge, relief valve, turbine flowmeter, high-pressure water pipe, ring-mounted water pipe, and nozzle; the experimental area is a semiclosed experimental box with a length of $2 \mathrm{~m}$, a width of $0.45 \mathrm{~m}$, and a height of $0.35 \mathrm{~m}$, as shown in Figure 9. During the experiment, the GM8903 thermal anemometer and vector frequency converter are connected to the computer to collect air-speed data and achieve the purpose of real-time detection. The turbine flowmeter is used to detect the working flow and working pressure of the pressure water output from the high-pressure atomizer. The chronometer is used to measure the time it takes for the new type of external pneumatic vortex fog curtain dust removal system to stabilize, thereby measuring 


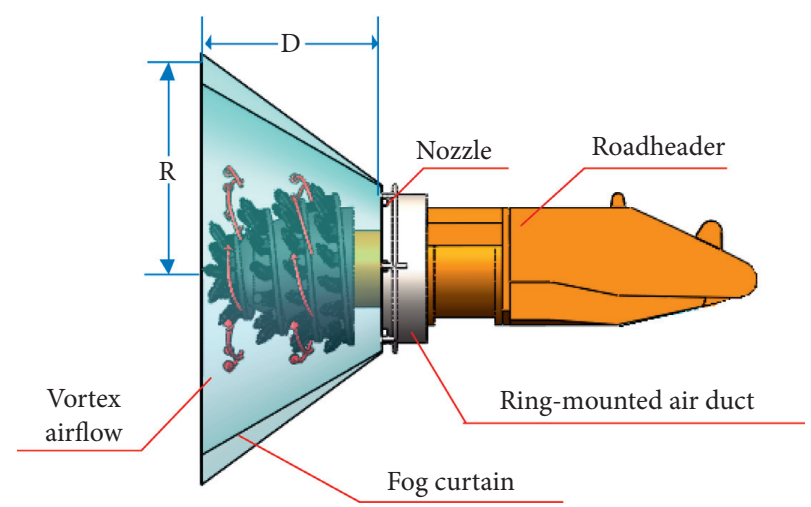

Figure 8: Ideal diagram of a new type of external aerodynamic vortex fog curtain (D represents the atomization range, and R represents the atomization radius).

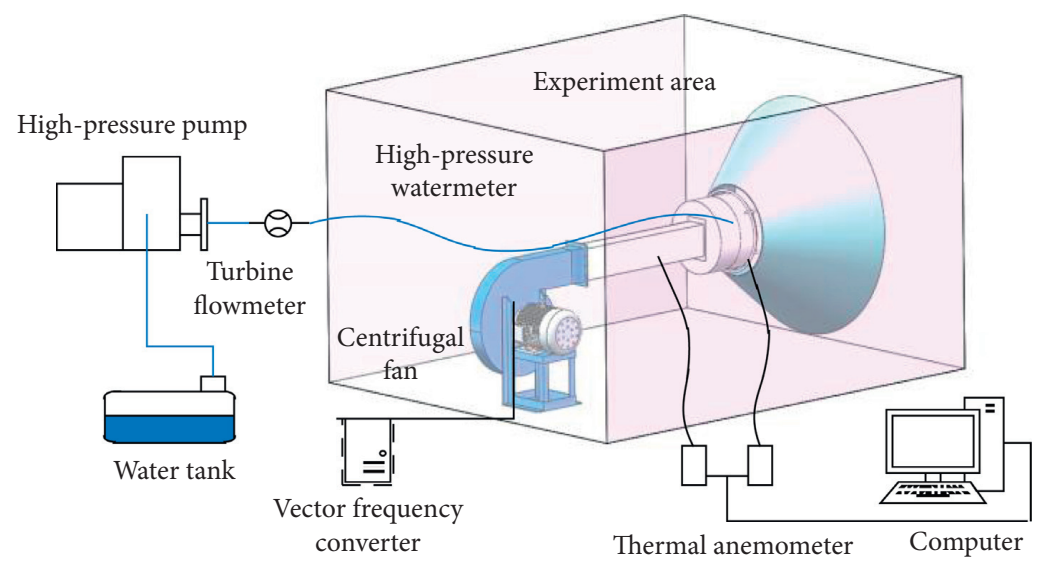

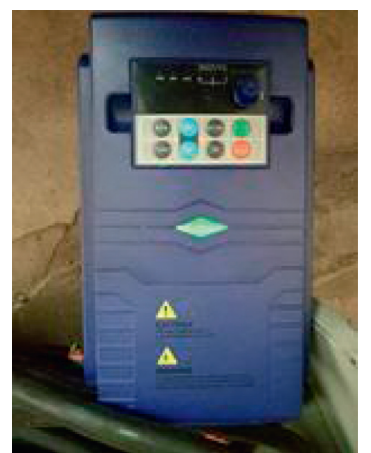

(a)

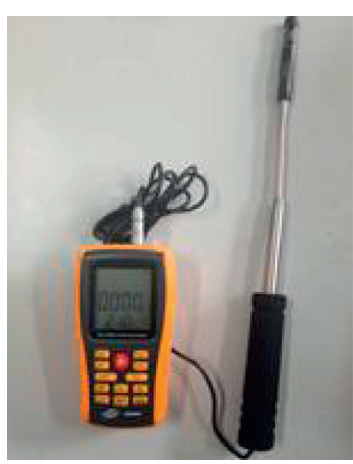

(b)

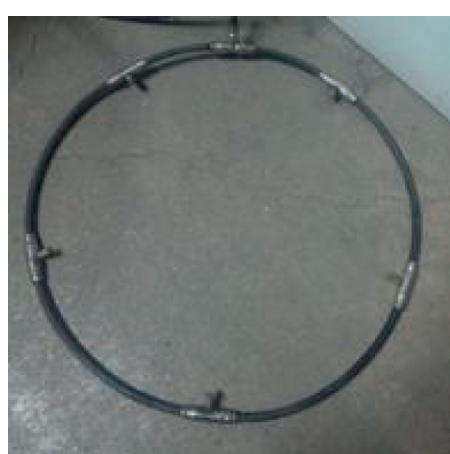

(c)

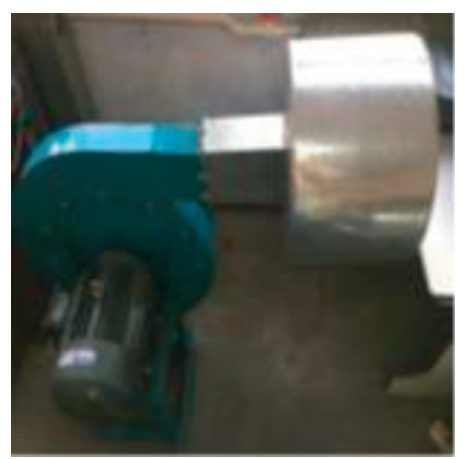

(d)

Figure 9: Schematic diagram of experimental device: (a) vector frequency converter, (b) thermal anemometer, (c) nozzles, and (d) centrifugal fan.

the volume flow of the fog curtain. The experimental process is as follows:

First bullet: the experimental equipment is connected according to the schematic diagram of the experimental device shown in Figure 9 to ensure that the joints are firmly connected.

Second bullet: the power switch is turned on, the centrifugal fan is started, the vector frequency converter is adjusted, and the intensity of the airflow output is controlled to the experimental conditions. When the output is stable, the working airspeed is measured.
Third bullet: the relief valve is kept open to $30 \%$, the high-pressure atomizer is started, and then the relief valve is closed; the pressure regulating controller is controlled on the high-pressure atomizer to change the output pressure of the high-pressure atomizer, and the pressure gauges are observed to rated working pressures of $4 \mathrm{MPa}, 6 \mathrm{MPa}$, and $8 \mathrm{MPa}$, respectively.

Fourth bullet: we make sure the pressure is stable during the experiment and measure the liquid flow with the turbine flowmeter.

Fifth bullet: when the airspeed at the exit of the highpressure airflow ejector is $20 \mathrm{~m} / \mathrm{s}, 25 \mathrm{~m} / \mathrm{s}$, and $30 \mathrm{~m} / \mathrm{s}$, 
the thermal anemometer (GM8903) is used to measure the atomization range and atomization radius at these three airspeeds, and test the atomization range and atomization radius of the spray nozzle under the conditions of $45^{\circ}, 60^{\circ}, 75^{\circ}, 90^{\circ}$, and $105^{\circ}$.

\section{Experimental Results and Discussion}

4.1. Experimental Results. To ensure the accuracy of experimental coverage, three repeated experiments were made in the same conditions. Under different jet wind speed, atomization pressure, and nozzle working angle, the atomization range and atomization radius of the new external pneumatic vortex fog curtain device are shown in Figures 10 and 11 . The vertical coordinate represents the nozzle working angle, and the horizontal coordinate represents the atomization range and atomization radius, respectively. The atomization performance data are shown in Table 1 .

4.2. Experimental Conclusions. Compared with Figures 10 and 11 and Table 1, it can be found that

(1) As the jet wind speed increases from $20 \mathrm{~m} / \mathrm{s}$ to $30 \mathrm{~m} /$ $\mathrm{s}$, the interference of the jet field on the droplet trajectory needs to be more obvious. When atomizing pressure and nozzle working angle remain the same, as the jet wind speed increases, the atomizing range decreases by $0.06-0.26 \mathrm{~m}$; as the jet wind speed increases, the atomizing radius increases by $0.15-0.35 \mathrm{~m}$. Therefore, the increase of the jet wind speed effectively increases the sealing performance of the fog curtain.

(2) When atomization pressure increased from $4 \mathrm{MPa}$ to $8 \mathrm{MPa}$, the atomization range increased and the fluctuation range was between 0 and $0.08 \mathrm{~m}$. However, the relationship between the atomization range and atomization pressure was not clear. When atomization pressure increased from $4 \mathrm{MPa}$ to $8 \mathrm{MPa}$, the atomization radius decreased, so the atomization pressure was $4 \mathrm{MPa}$ and the atomization performance was the highest.

(3) The increase of the nozzle working angle takes such atomization range change course under the same atomization pressure and jet wind speed. The atomizing radius first increases and then decreases with the increase of the nozzle working angle, and the maximum atomizing radius is obtained at $75^{\circ}$; when the nozzle working angle exceeds $90^{\circ}$, the interphase interference of the two-phase flow field decreases, and the direction of the fog field is gradually parallel to the jet field; the radial diffusion effect of the droplets and the atomization radius are reduced, but the atomization range becomes larger. When the nozzle working angle is $105^{\circ}$, the atomization range and the atomization radius are the smallest. Therefore, when jet wind speed is $30 \mathrm{~m} / \mathrm{s}$, the atomization pressure is $4 \mathrm{MPa}$, and the nozzle working angle is $75^{\circ}$, the new type of external pneumatic vortex fog curtain dust removal device obtains the best atomizing radius and sealing performance.

\section{Pressure Wind Effect and Dust- Reduction Efficiency}

5.1. Simulation of Influence of Pressure Wind. According to the measurement results of the actual size of the heading face in the underground coal mine of Mugua coal mine in Huozhou, Shanxi Province, a three-dimensional full-scale tunnel physical model with a width of $4.5 \mathrm{~m}$, a height of $3.5 \mathrm{~m}$, and a length of $20 \mathrm{~m}$ was built using Solidworks (3D modeling software). The cross-sectional area $S$ is $15.75 \mathrm{~m}^{2}$. The length, width, and height of the heading machine in the tunnel physical model are $9.3 \mathrm{~m} \times 2.9 \mathrm{~m} \times 1.8 \mathrm{~m}$. Ventilation ducts are $800 \mathrm{~mm}$ diameter flame-retardant ducts, as shown in Figure 12. To make the dust-reducing effect good, the jet wind speed of the new type of external pneumatic vortex fog curtain dust removal device is set to $v=30 \mathrm{~m} / \mathrm{s}$, the nozzle working angle is set to $75^{\circ}$, and the atomization pressure is set to $4 \mathrm{MPa}$. According to the relevant regulations of China, $Q$ pressure of the heading face of coal roadway is $\geq 9 \mathrm{~s}$ and $\leq 240$ s, so the minimum air volume of the heading face is $141.75 \mathrm{~m}^{3} / \mathrm{min}$ and the maximum is $3780 \mathrm{~m}^{3} / \mathrm{min}$. Therefore, set $Q$ pressure of air outlet as $150 \mathrm{~m}^{3} / \mathrm{min}, 300 \mathrm{~m}^{3} / \mathrm{min}$, $400 \mathrm{~m}^{3} / \mathrm{min}$, and $500 \mathrm{~m}^{3} / \mathrm{min}$. Based on the similar theory, to simulate the effect of the pressure outlet on the movement trajectory of the droplet under different air volume conditions, a physical model with a width of $0.45 \mathrm{~m}$, a height of $0.35 \mathrm{~m}$, and a length of $2 \mathrm{~m}$ was established using COMSOL software. $Q$ pressure of the air outlet is set to $1.5 \mathrm{~m}^{3} / \mathrm{min}$, $3 \mathrm{~m}^{3} / \mathrm{min}, 4 \mathrm{~m}^{3} / \mathrm{min}$, and $5 \mathrm{~m}^{3} / \mathrm{min}$, and the regularity of particle trajectories with time is shown in Figures 13-16. Compared with Figures 13-16, the following findings are found:

When the new type of external pneumatic vortex fog curtain dust removal device works stably, after the air flows out from the pressure outlet, a jet field directed to the wall is formed at the front end of the pressure outlet with high airspeed, and at the same time, the jet impacts the wall surface and bounces. With the increase of pressure outlet airspeed, the impact strength of the airflow effective jet field of the pressure outlet gradually increases. With the increase of the jet wind speed produced by the pressure air duct, the interference of the airflow at the pressure outlet on the movement of the new type of external pneumatic vortex fog curtain dust removal device becomes more and more obvious, which makes the movement direction of the originally rotating and diffusing droplets change, and the pneumatic vortex fog curtain gradually presents a gap with the increase of the airspeed.

When the air volume is $1.5 \mathrm{~m}^{3} / \mathrm{min}, 3 \mathrm{~m}^{3} / \mathrm{min}, 4 \mathrm{~m}^{3} / \mathrm{min}$, and $5 \mathrm{~m}^{3} / \mathrm{min}$, the integrality of the fog curtain is complete, relatively complete, relatively divergent, and divergent, respectively; when the air volume of the pressure outlet is more than $3 \mathrm{~m}^{3} / \mathrm{min}$, the diffusion distance of the droplets in the working face increases with the increase of the wind speed, forming a greater impact diffusion on the pneumatic vortex 


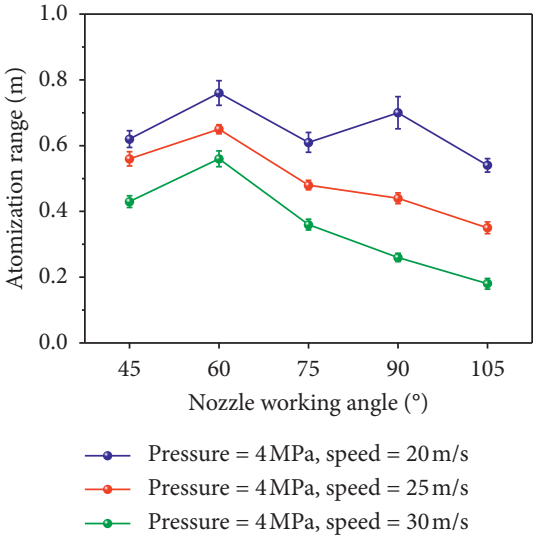

(a)

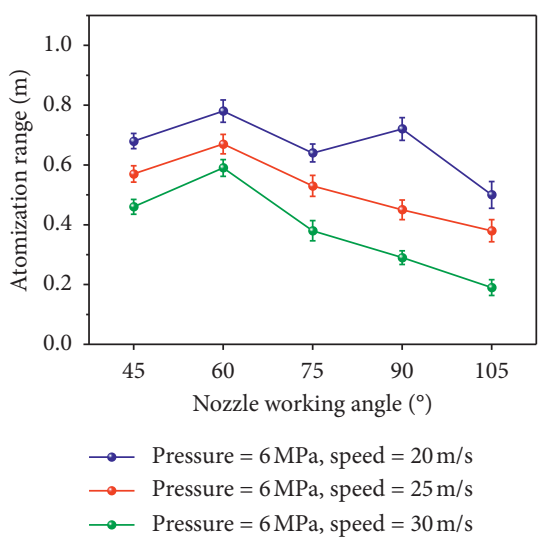

(b)

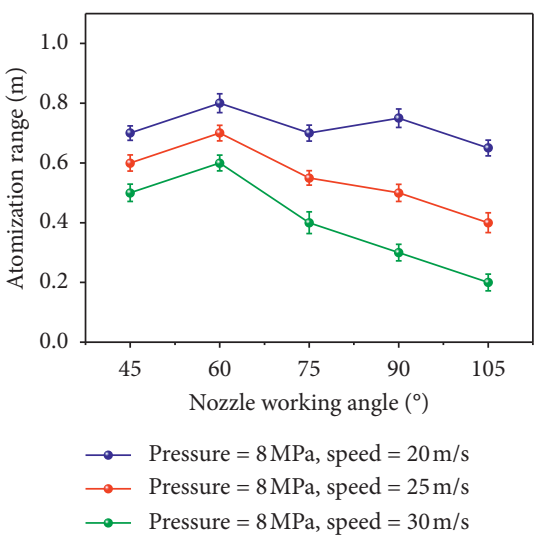

(c)

FIGURE 10: Atomization range at different pressures: (a) pressure $4 \mathrm{MPa}$, (b) pressure $6 \mathrm{MPa}$, and (c) pressure $8 \mathrm{MPa}$.

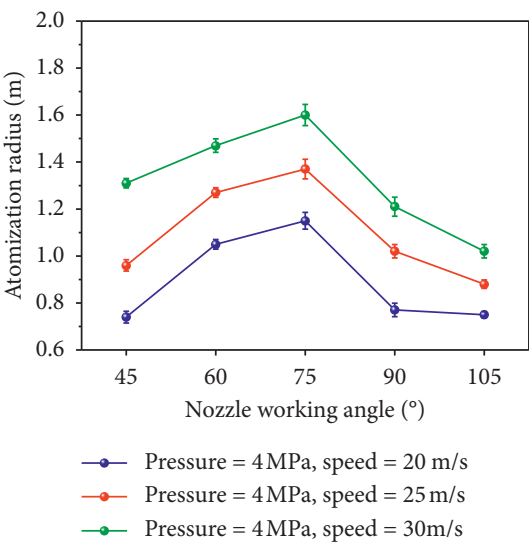

(a)

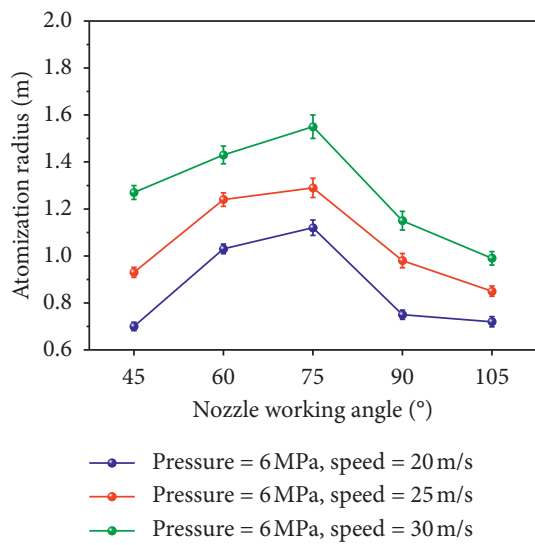

(b)

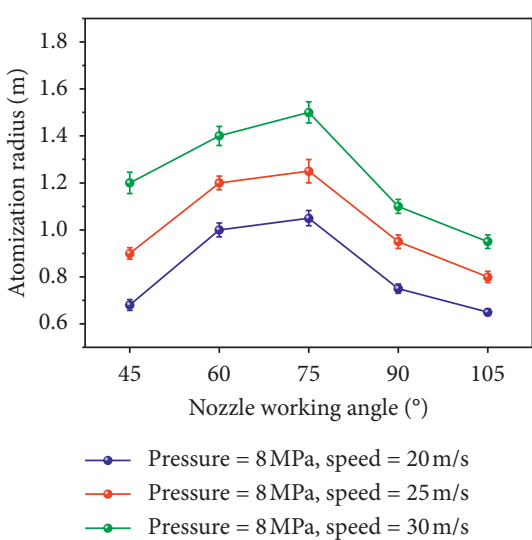

(c)

Figure 11: Atomization radius at different pressures: (a) pressure $4 \mathrm{MPa}$, (b) pressure $6 \mathrm{MPa}$, and (c) pressure $8 \mathrm{MPa}$.

TABle 1: Atomization performance data table.

\begin{tabular}{|c|c|c|c|c|c|c|c|}
\hline \multirow{2}{*}{ Jet wind speed $(\mathrm{m} / \mathrm{s})$} & \multirow{2}{*}{ Nozzle working angle $\left({ }^{\circ}\right)$} & \multicolumn{2}{|c|}{ Pressure $(4 \mathrm{MPa})$} & \multicolumn{2}{|c|}{ Pressure (6 MPa) } & \multicolumn{2}{|c|}{ Pressure $(8 \mathrm{MPa})$} \\
\hline & & Range (m) & Radius (m) & Range (m) & Radius (m) & Range (m) & Radius (m) \\
\hline \multirow{5}{*}{$20 \mathrm{~m} / \mathrm{s}$} & $45^{\circ}$ & 0.62 & 0.74 & 0.68 & 0.7 & 0.7 & 0.68 \\
\hline & $60^{\circ}$ & 0.76 & 1.05 & 0.78 & 1.03 & 0.8 & 1 \\
\hline & $75^{\circ}$ & 0.61 & 1.15 & 0.64 & 1.12 & 0.7 & 1.05 \\
\hline & $90^{\circ}$ & 0.7 & 0.77 & 0.72 & 0.75 & 0.75 & 0.75 \\
\hline & $105^{\circ}$ & 0.54 & 0.75 & 0.5 & 0.72 & 0.65 & 0.65 \\
\hline \multirow{5}{*}{$25 \mathrm{~m} / \mathrm{s}$} & $45^{\circ}$ & 0.56 & 0.96 & 0.57 & 0.93 & 0.6 & 0.9 \\
\hline & $60^{\circ}$ & 0.65 & 1.27 & 0.67 & 1.24 & 0.7 & 1.2 \\
\hline & $75^{\circ}$ & 0.48 & 1.37 & 0.53 & 1.29 & 0.55 & 1.25 \\
\hline & $90^{\circ}$ & 0.44 & 1.02 & 0.45 & 0.98 & 0.5 & 0.95 \\
\hline & $105^{\circ}$ & 0.35 & 0.88 & 0.38 & 0.85 & 0.4 & 0.8 \\
\hline \multirow{5}{*}{$30 \mathrm{~m} / \mathrm{s}$} & $45^{\circ}$ & 0.43 & 1.31 & 0.46 & 1.27 & 0.5 & 1.2 \\
\hline & $60^{\circ}$ & 0.56 & 1.47 & 0.59 & 1.43 & 0.6 & 1.4 \\
\hline & $75^{\circ}$ & 0.36 & 1.6 & 0.38 & 1.55 & 0.4 & 1.5 \\
\hline & $90^{\circ}$ & 0.26 & 1.21 & 0.29 & 1.15 & 0.3 & 1.1 \\
\hline & $105^{\circ}$ & 0.18 & 1.02 & 0.19 & 0.99 & 0.2 & 0.95 \\
\hline
\end{tabular}




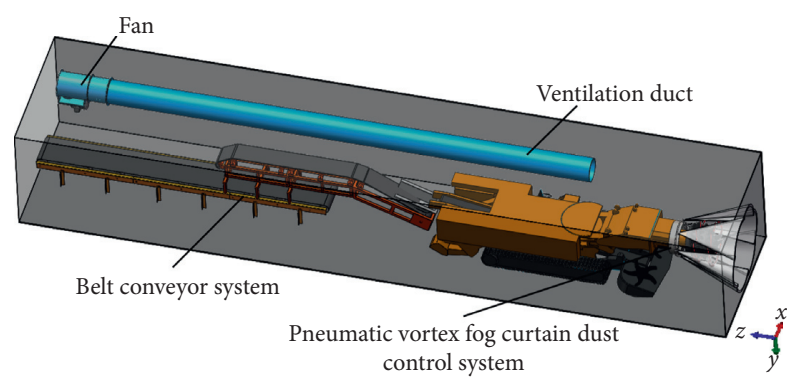

FIgURE 12: Physical model of a new type of external pneumatic vortex fog curtain dust removal device integrated dust control system in fully mechanized excavation face.

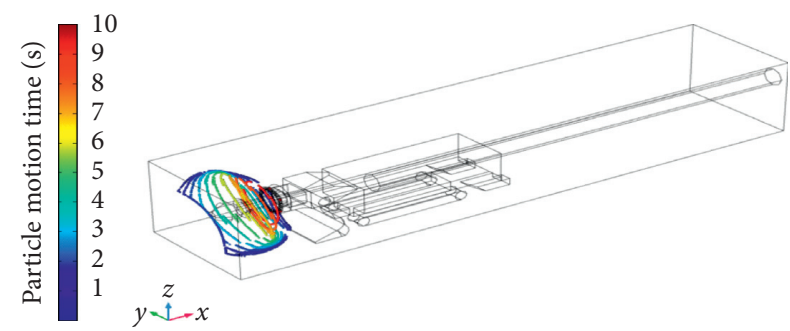

FIGURE 13: Particle trajectory with an air volume of $1.5 \mathrm{~m}^{3} / \mathrm{min}$.

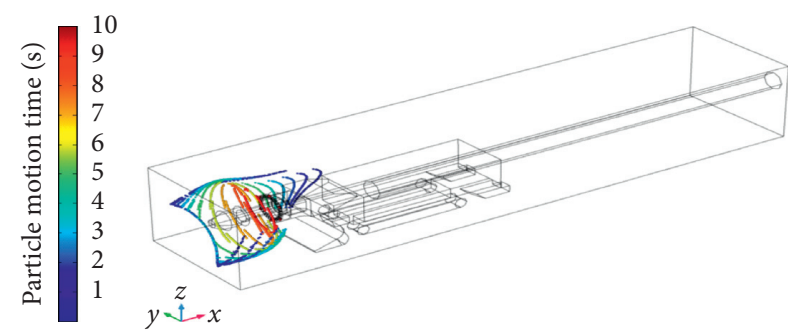

Figure 14: Particle trajectory with an air volume of $3 \mathrm{~m}^{3} / \mathrm{min}$.

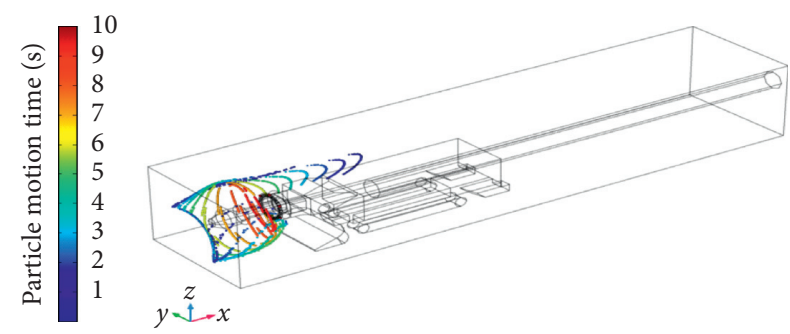

Figure 15: Particle trajectory with an air volume of $4 \mathrm{~m}^{3} / \mathrm{min}$.

fog curtain; when the air volume of the pressure outlet reaches $4 \mathrm{~m}^{3} / \mathrm{min}$, the new type of external pneumatic vortex fog curtain dust removal device can withstand the maximum interference of ventilation airflow; when the air volume of the pressure outlet reaches $5 \mathrm{~m}^{3} / \mathrm{min}$, with the increase of the air volume of the pressure outlet, the phenomenon of fog droplet diffusion is intensified, and the gap is continuously expanded, and the rotating fog curtain formed by the fog droplets is completely destroyed by the pressure air, making

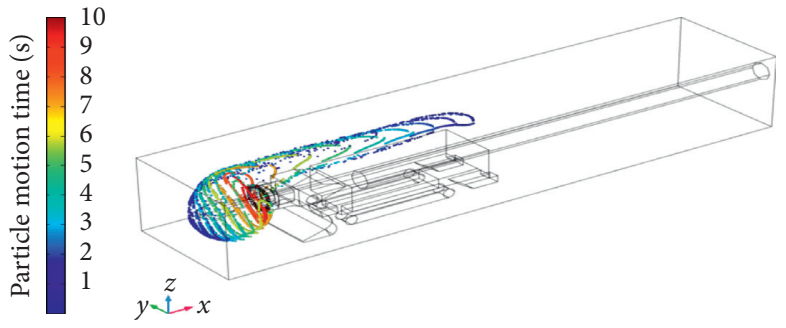

FIGURE 16: Particle trajectory with an air volume of $5 \mathrm{~m}^{3} / \mathrm{min}$.

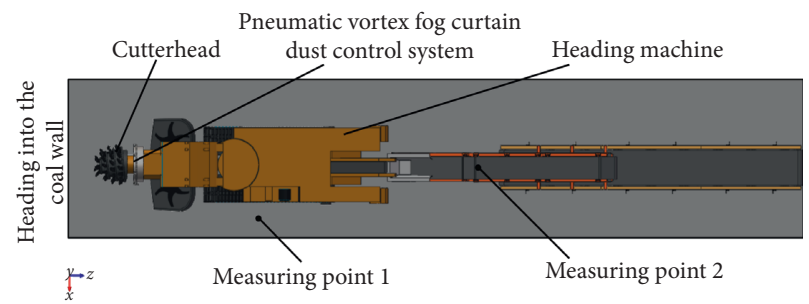

FIGURE 17: Experimental measurement point location.

the new type of external pneumatic vortex fog curtain dust removal device invalid.

5.2. Dust-Reduction Efficiency. When the new type of external pneumatic vortex fog curtain dust removal device is turned on, the humidity in the confined space under the mine is high, and small droplets moving in the space with the pressure airflow field cover the entire roadway, which seriously affects the dust control accuracy of the laser dust concentration meter. Therefore, it is necessary to use the dust sampler to sample the dust in the air. In the experiment, a self-made dust generator was set as a dust source in a semiclosed experiment box with a length $\times$ width $\times$ height of $2 \mathrm{~m} \times 0.45 \mathrm{~m} \times 0.35 \mathrm{~m}$. The dust used in the experiment comes from the raw coal of the Fuxin Power Plant. After the raw coal is crushed, the larger diameter coal dust is removed using a sieve with a mesh size of $0.045 \mathrm{~mm}$ for dust generation. The dust emission is performed at $30 \mathrm{~g} / \mathrm{min}$. With the increase of the unit mass of the front and rear filter membranes and the flow rate of the equipment sampling, the mass concentration of dust in the air can be obtained according to the formula. According to the simulation conclusion in Section 5.1, the dust-reduction experiment was performed under the conditions that can form a relatively complete fog curtain. The experimental conditions include the following.

Condition 1. The dust generator is turned on separately (using the CCZ-1000 laser dust concentration sampler).

Condition 2. The pneumatic vortex fog curtain dust control system is turned on, the compressed air duct is turned on, and a dust sampler is used to measure the dust concentration distribution at the measurement point (the atomizing pressure is $4 \mathrm{MPa}$, the nozzle working angle is $75^{\circ}$, and the jet wind speed is $30 \mathrm{~m} / \mathrm{s}$, and the air volume of 
TABLE 2: Total dust sampling concentration.

\begin{tabular}{|c|c|c|c|c|c|c|c|}
\hline \multirow[b]{2}{*}{ Condition } & \multicolumn{7}{|c|}{ Project } \\
\hline & $\begin{array}{l}\text { Measurement } \\
\text { point }\end{array}$ & $\begin{array}{l}\text { Dwell time } \\
(\min )\end{array}$ & $\begin{array}{c}\text { Flow } \\
\left(\mathrm{L} \cdot \mathrm{min}^{-1}\right)\end{array}$ & $\begin{array}{l}\text { Filter weight } \\
(\mathrm{mg})\end{array}$ & $\begin{array}{l}\text { Filter weight } \\
\text { gain }(\mathrm{mg})\end{array}$ & $\begin{array}{l}\text { Net weight } \\
(\mathrm{mg})\end{array}$ & $\begin{array}{l}\text { Total dust concentration } \\
\left(\mathrm{mg} \cdot \mathrm{m}^{-3}\right)\end{array}$ \\
\hline Condition 1 & 1 & - & - & - & - & - & 433.9 \\
\hline Condition 1 & 2 & - & - & - & - & - & 306.8 \\
\hline Condition 2 (1) & 1 & 2 & 20 & 89.8 & 90.3 & 0.5 & 12.5 \\
\hline Condition 2 (1) & 2 & 2 & 20 & 88.9 & 89.2 & 0.3 & 7.5 \\
\hline Condition 2 (2) & 1 & 2 & 20 & 85.4 & 85.9 & 0.5 & 12.5 \\
\hline Condition 2 (2) & 2 & 2 & 20 & 87.3 & 88 & 0.7 & 17.5 \\
\hline Condition 2 (3) & 1 & 2 & 20 & 90.1 & 90.5 & 0.4 & 10 \\
\hline Condition 2 (3) & 2 & 2 & 20 & 82.3 & 83.6 & 1.3 & 32.5 \\
\hline
\end{tabular}

TABLE 3: Sampling concentration of respirable dust.

\begin{tabular}{|c|c|c|c|c|c|c|c|}
\hline \multirow[b]{2}{*}{ Condition } & \multicolumn{7}{|c|}{ Project } \\
\hline & $\begin{array}{l}\text { Measurement } \\
\text { point }\end{array}$ & $\begin{array}{l}\text { Dwell time } \\
(\mathrm{min})\end{array}$ & $\begin{array}{c}\text { Flow } \\
\left(\mathrm{L} \cdot \mathrm{min}^{-1}\right)\end{array}$ & $\begin{array}{c}\text { Filter } \\
\text { weight }(\mathrm{mg})\end{array}$ & $\begin{array}{l}\text { Filter weight } \\
\text { gai }(\mathrm{mg})\end{array}$ & $\begin{array}{l}\text { Net weight } \\
(\mathrm{mg})\end{array}$ & $\begin{array}{l}\text { Respirable dust concentration } \\
\left(\mathrm{mg} \cdot \mathrm{m}^{-3}\right)\end{array}$ \\
\hline Condition 1 & 1 & - & - & - & - & - & 135.5 \\
\hline Condition 1 & 2 & - & - & - & - & - & 70.2 \\
\hline Condition 2 (1) & 1 & 2 & 20 & 89.8 & 90.1 & 0.3 & 7.5 \\
\hline Condition 2 (2) & 2 & 2 & 20 & 87.3 & 87.4 & 0.1 & 2.5 \\
\hline Condition 2 (1) & 1 & 2 & 20 & 85.4 & 85.6 & 0.2 & 5 \\
\hline Condition 2 (2) & 2 & 2 & 20 & 89.9 & 90.1 & 0.2 & 5 \\
\hline Condition 2 (1) & 1 & 2 & 20 & 87.3 & 87.4 & 0.1 & 2.5 \\
\hline Condition 2 (2) & 2 & 2 & 20 & 85.7 & 86.1 & 0.4 & 10 \\
\hline
\end{tabular}

the pressure outlet is $1.5 \mathrm{~m}^{3} / \mathrm{min}, 3 \mathrm{~m}^{3} / \mathrm{min}$, and $4 \mathrm{~m}^{3}$ / $\min )$.

According to the requirements for dust detection in China's safety production industry standard "Technical Specifications for Comprehensive Dust Control Measures for Underground Coal Mine (AQ1020-2006)," two dust detection points are arranged at the driver's position of the roadheader and $0.5 \mathrm{~m}$ behind the roadheader body $(1.5 \mathrm{~m}$ from the height of the breathing belt of the floor staff). The position of measuring point 1 is $0.75 \mathrm{~m}$ from the driver's position, and the breathing zone height is $0.15 \mathrm{~m}$. The measuring point 2 is $1.5 \mathrm{~m}$ behind the unit's return air, and the breathing zone height is $0.15 \mathrm{~m}$. The arrangement of measuring points is shown in Figure 17. The distribution of dust concentration under different working conditions is shown in Tables 2 and 3. According to the dust concentration obtained in the table, the calculation of the dustreduction efficiency of dust prevention measures can be calculated according to the following formula:

$$
\eta=\frac{c_{1}-c_{0}}{c_{0}} \times 100 \%
$$

where $\eta$ is the average dust-reduction efficiency of dustproof measures, $\%$; $c_{0}$ is the average dust concentration before taking some dust prevention measures, $\mathrm{mg} / \mathrm{m}^{3}$; and $c_{1}$ is the average dust concentration after taking some dust protection measures, $\mathrm{mg} / \mathrm{m}^{3}$. When the $Q$ pressure is calculated to be $1.5 \mathrm{~m}^{3} / \mathrm{min}, 3 \mathrm{~m}^{3} / \mathrm{min}$, and $4 \mathrm{~m}^{3} / \mathrm{min}$, the total dust-reduction efficiency at the measurement point 1 is $97.1 \%, 97.1 \%$, and $97.7 \%$, respectively; the respiratory dust-reduction efficiency is $94.5 \%, 96.3 \%$,

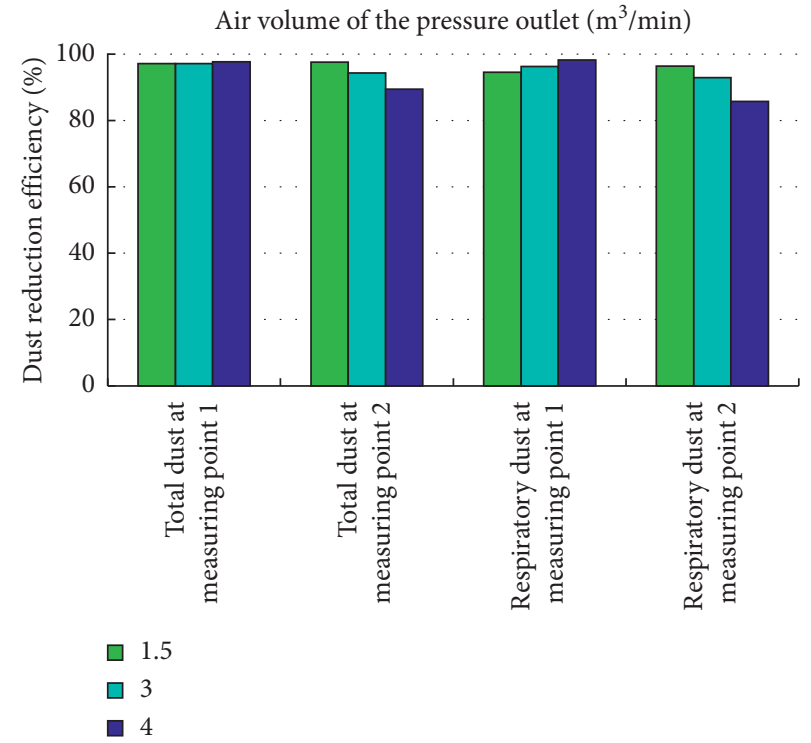

FIGURE 18: Dust-reduction efficiency at measuring points 1 and 2.

and $98.2 \%$. Total dust-reduction efficiency at the measurement point 2 is $97.6 \%, 94.3 \%$, and $89.4 \%$, respectively; the respiratory dust-reduction efficiency is $96.4 \%$, $92.9 \%$, and $85.8 \%$, respectively. It can be consulted from Figure 18 that at the measurement point 1 , as the air volume of the pressure outlet increases, the dust-reduction efficiency increases. This is because the airspeed of the pressure outlet increases and the dust diffuses with the wind and does not return to the driver's seat, so the 
dust concentration at the driver's measuring point 1 decreases. With the increase of air volume, the gap appeared in the pneumatic fog curtain which was originally closed to the heading wall, which caused the front dust to break through the gap of the fog curtain and spread backward, and the dust concentration at measuring point 2 behind the roadheader increased.

\section{Conclusion}

To solve the dust pollution problem of the driving face, a new type of external pneumatic vortex fog curtain dust removal device suitable for a fully mechanized face was designed. The following conclusions were obtained through simulation and experiment:

(1) Using COMSOL to simulate the particle movement at different times, it was found that the dust pollution near the head of the roadheader was serious, and it quickly spread to the working space behind the roadheader. Even under 3 different wind speeds, the dust concentration at the height of $1.5 \mathrm{~m}$ is the largest.

(2) Through the self-designed spray atomization experiment platform, the atomization performance of the device was tested, and it was found that the nozzle working angle, jet wind speed, and atomization pressure have effects on the atomization range and atomization radius. Under the conditions of a jet wind speed of $30 \mathrm{~m} / \mathrm{s}$, an atomization pressure of $4 \mathrm{MPa}$, and a nozzle working angle of $75^{\circ}$, the new type of external pneumatic vortex fog curtain dust removal device obtained the best atomizing radius and sealing performance.

(3) Through the research on the anti-interference and dust suppression performance of the new type of external pneumatic vortex fog curtain dust removal device, it is found that the device is more stable when the air volume of the pressure outlet is lower than $400 \mathrm{~m}^{3} / \mathrm{min}$. Under the condition that the ventilation conditions do not interfere with the integrity of the vortex fog screen, the dust-reduction efficiency of the new external pneumatic vortex fog screen dust removal device is above $90 \%$, and the dust-reduction effect is good.

\section{Data Availability}

All data used to support the study are present in the article as figures or tables.

\section{Conflicts of Interest}

The authors declare no conflicts of interest.

\section{Acknowledgments}

This research was funded by the National Natural Science Foundation of China, grant no. 51704146.

\section{References}

[1] S. P. Peng, "China coal resources development and environmental protection," Science and Technology Herald, vol. 27, no. 17, p. 3, 2009.

[2] P. R. Amyotte, M. J. Pegg, F. I. Khan et al., "Moderation of dust explosions," Journal of Loss Prevention in the Process Industries, vol. 20, no. 4-6, pp. 675-687, 2007.

[3] X. Liu, Research and Application of Extension Comprehensive Evaluation of Mine Dust Danger, Taiyuan University of Technology, Taiyuan, China, 2014.

[4] H. Y. Zhang, "Application of fully mechanization in coal mines mining," Coal Technology, vol. 31, no. 1, p. 26, 2012.

[5] B. Fabiano, F. Currò, A. P. Reverberi, and E. Palazzi, "Coal dust emissions: from environmental control to risk minimization by underground transport. An applicative casestudy," Process Safety and Environmental Protection, vol. 92, no. 2, pp. 150-159, 2014.

[6] E. L. Petsonk, C. Rose, and R. Cohen, "Coal mine dust lung disease. New lessons from an old exposure," American Journal of Respiratory and Critical Care Medicine, vol. 187, no. 11, pp. 1178-1185, 2013.

[7] M. Y. Hai, M. Wei, X. Yao, and H. T. Peng, "Micro-scale pollution mechanism of dust diffusion in a blasting driving face based on CFD-DEM coupled model," Environmental Science and Pollution Research, vol. 25, no. 22, pp. 2176821788, 2018.

[8] Y. H. Sheng, R. F. Guo, Y. R. Xiang et al., "Numerical study of gas-solid two-phase flow in a coal roadway after blasting," Advanced Powder Technology, vol. 27, no. 4, pp. 1607-1617, 2016.

[9] V. Castranova and V. Vallyathan, "Silicosis and coal workers' pneumoconiosis," Environmental Health Perspectives, vol. 108, no. 4, pp. 675-684, 2000.

[10] L. Han, R. Han, X. Ji et al., "Prevalence characteristics of coal workers' pneumoconiosis (CWP) in a state-owned mine in eastern China," International Journal of Environmental Research and Public Health, vol. 12, no. 7, pp. 7856-7867, 2015.

[11] S. L. Yang, "Numerical simulation of 3-Dimensional dust distribution on long wall coal faces," China Safety Science Journal, vol. 4, no. 16, pp. 64-67, 2001.

[12] P. F. Wang, T. Feng, and R. H. Liu, "Numerical simulation of dust distribution at a fully mechanized face under the isolation effect of an air curtain," Mining Science and Technology, vol. 21, no. 1, pp. 65-69, 2011.

[13] Y. J. Li, P. F. Wang, and R. H. Liu, "Influence of the stripshaped air-out slit' width in the fully mechanized working face under wallattached swirling ventilation," E3S Web of Conferences, vol. 81, no. 1, Article ID 01016, 2019.

[14] Q. Liu, W. Nie, Y. Hua, H. Peng, C. Liu, and C. Wei, "Research on tunnel ventilation systems: dust Diffusion and Pollution Behaviour by air curtains based on CFD technology and field measurement," Building and Environment, vol. 147, no. 1, pp. 444-460, 2019.

[15] H. Yu, W. Cheng, H. Wang, H. Peng, and Y. Xie, "Formation mechanisms of a dust-removal air curtain in a fully-mechanized excavation face and an analysis of its dust-removal performances based on CFD and DEM," Advanced Powder Technology, vol. 28, no. 11, pp. 2830-2847, 2017.

[16] S. C. Ge, D. J. Jing, and Y. P. Huang, "Mumerical simulation determination of the production mechanism and technical parameters of high-pressure micro-fog system," Journal of Liaoning Technical University, vol. 1, no. 7, pp. 17-20, 2012. 
[17] X. Chen, S. C. Ge, Z. W. Zhang, and D. J. Jing, "Numerical simulation and analysis of multi-nozzle interference base on Fluent," Chinese Journal of Environmental Engineering, vol. 8, no. 6, pp. 2503-2508, 2014.

[18] X. Chen and S. C. Ge, "Numerical and experimental study on spray characteristics with effect of induced airflow on transshipment point," Journal of China Coal Society, vol. 40, no. 3, pp. 603-608, 2015.

[19] X. Chen and S. C. Ge, "Numerical simulation of high-pressure spray coal dust capture technology based on fluent software and its application," China Safety Science Journal, vol. 23, no. 8, pp. 144-149, 2013.

[20] H. T. Liu, Numerical Simulation of Micro-particle Deposition and Diffusion Characteristics in Gas-Solid Two-phase Flow, Chongqing University, Chongqing, China, 2012.

[21] Z. Liu and H. X. Liu, "Simulation for the flow field of the turbulence coalescence device and the trajectory of particles," Proceedings of the CSEE, vol. 32, no. 14, pp. 71-75, 2012.

[22] G. Pu, L. Zhang, and M. D. Xin, "Numerical simulation and optimization of gas-solid two-phase flow in one CFBC cyclone separator," Journal of Engineering Thermophysics, vol. 27, no. 2, pp. 268-270, 2006.

[23] L. X. Zhou and H. X. Gu, "Simulation of swirling gas-particle flows using a nonlinear k- $\varepsilon$-kp two-phase turbulence model," Powder Technology, vol. 128, no. 1, pp. 47-55, 2002.

[24] H. R. Nazif and H. Basirat Tabrizi, "Development of boundary transfer method in simulation of gas-solid turbulent flow of a riser," Applied Mathematical Modelling, vol. 37, no. 4, pp. 2445-2459, 2013.

[25] J. Y. Mo, Effect of Inter-phase Drag Law in CFD Simulation of Liquid Characteristics in a Solid-Liquid Stirred Tank, Beijing University of Chemical Technology, Beijing, China, 2012.

[26] Z. X. Ceng, C. B. Hu, P. Z. Jiang, and L. Q. Kang, "Analysis of dense, turbulent, compressible, gas-particle two-phase flow and its application to pipe flow," Journal of Acta Aerodynamica Sinica.vol. 19, no. 1, pp. 109-118, 2001.

[27] Y. P. Tsuo and D. Gidaspow, "Computation of flow patterns in circulating fluidized beds," AIChE Journal, vol. 36, no. 6, pp. 885-896, 1990. 